\title{
Prevalence and factors associated with polypharmacy in the older people: $2006-2014$
}

\author{
Juan Manuel Carmona-Torres PhD, RN, Professor ${ }^{1,2}$ (D) | Ana Isabel Cobo-Cuenca PhD, RN, \\ Professor $^{1,2}$ (1) | Beatriz Recio-Andrade RN, Clinical Nurse ${ }^{3}$ | José Alberto Laredo-Aguilera \\ PhD, RN, Professor ${ }^{4}$ (D) María Manuela Martins PhD, RN, Full Professor ${ }^{5}$ | María \\ Aurora Rodríguez-Borrego PhD, RN, Full Professor $2,6,7$
}

${ }^{1}$ E. U. Enfermería y Fisioterapia de Toledo, Universidad de Castilla-La Mancha, Toledo, Spain

${ }^{2}$ Instituto Maimónides de Investigación Biomédica de Córdoba (IMIBIC), Córdoba, Spain

${ }^{3}$ Hospital Virgen de la Salud, Toledo, Spain

${ }^{4}$ Facultad de Terapia Ocupacional, Logopedia y Enfermería de Talavera de la Reina, Universidad de Castilla-La Mancha, Talavera de la Reina, Spain

${ }^{5}$ Escola de Enfermagem do Porto/ICBAS, UP - Grupo de Investigação - NursID: Inovação e Desenvolvimento em Enfermagem, CINTESIS - center for health technology and services research - FMUP, Porto, Portugal

${ }^{6}$ Facultad de Medicina y Enfermería, Universidad de Córdoba, Córdoba, Spain

${ }^{7}$ Hospital Universitario Reina Sofía, Córdoba, Spain

\section{Correspondence}

Juan Manuel Carmona-Torres, Escuela Universitaria de Enfermería y Fisioterapia de Toledo, Toledo, Spain.

Email: juanmanuel.carmona@uclm.es
Aims and objectives: To analyse the prevalence, risk factors and evolution over time of polypharmacy and self-medication in the older people in Spain from 20062014.

Background: Polypharmacy is a public health problem for older people worldwide which causes different negative effects on their health, increasing health costs and pharmaceutical spending. However, previous studies do not include nationally representative samples and none of them provide updated data.

Design: Cross-sectional study with community-dwelling older adults $(N=26,277)$ who participated in the National Health Survey in Spain in 2006 and 2011/2012 and the European Health Survey in Spain in 2009 and 2014.

Methods: Polypharmacy (defined as use of five or more medications in the last 2 weeks), excessive polypharmacy (defined as use of ten or more medications in the last 2 weeks) and self-medication (defined as use of medications without a prescription) were evaluated. A logistic regression was used for to know the association between polypharmacy and self-medication with the sociodemographic characteristic.

Results: The participants were $62 \%$ female and $38 \%$ male. The mean medication consumption was $2.96(S D \pm 2.11)$. Prevalence of polypharmacy was present in $21.9 \%$, prevalence of excessive polypharmacy was $0.6 \%$, and prevalence of selfmedication was $10.7 \%$. The most commonly used medications were for blood pressure $(51.6 \%)$, pain (42.8\%) and cholesterol (28.2\%). Polypharmacy is associated with sex (females), age, being separated/divorced/widowed, lack of education, higher body mass index, being bedridden during the last 2 weeks and self-medication.

Conclusions: The prevalence of polypharmacy and prevalence of self-medication are considerable, and they increased significantly from 2006-2014.

Relevance to clinical practice: To deal with polypharmacy is a big challenge for nurses. These data suggest to establish innovative clinical strategies in which the health professionals and the patients are involved to improve the personal behaviour with medicines and to reduce the risks and costs of polypharmacy and self-medication. 
KEYWORDS

aged, medication, polypharmacy, public health, self-medication, Spain

\section{1 | INTRODUCTION}

The world's population is ageing; it is estimated that between 20152030 , the number of people aged 60 and over will grow by $56 \%$ worldwide. In Europe, older people (OP) over 60 years will increase from $19.8 \%$ in 2015 to $23.1 \%$ in 2030 (United Nations, 2015). In Spain, it is estimated that the population over 60 years of age will constitute $33.5 \%$ of the total population by 2030 (United Nations, 2015). Age is associated with increases in chronic diseases, functional limitations and morbidity, resulting in a greater use of health services and increased consumption of drugs (Fried et al., 2014; Lopes, Figueiredo, Costa, \& Reis, 2016), which becomes a challenge for the health system (Lutz, Miranda, \& Bertoldi, 2017).

The use of multiple medications by a person (usually $\geq 5$ ) is defined as "polypharmacy" (Aguirre et al., 2017), although there is currently no consensus on this definition in the literature (Maher, Hanlon, \& Hajjar, 2014). Polypharmacy has also been defined as the use of more medications than is medically necessary. Within polypharmacy, medications dispensed without prescription should be included (Aguirre et al., 2017), that is self-medication, defined as the selection and use of medications chosen by the patient for the treatment of a disease and/or symptoms perceived by them (Arrais et al., 2016). Therefore, self-medication is a potential cause of polypharmacy (Mortazavi et al., 2016).

Changes in age-related pharmacokinetics and pharmacodynamics (due to decreases in body mass, body water content, renal function, liver function and serum albumin levels), together with polypharmacy, produce negative health effects in the older people (Fried et al., 2014; Gnjidic et al., 2012), such as adverse drug effects (Cabello et al., 2016), falls (López-Soto, García-Arcos, Fabbian, Manfredini, \& Rodríguez-Borrego, 2017), increased use of health services (Gnjidic et al., 2012), increased health costs (Martin, Hartman, Benson, \& Catlin, 2016) and use of potentially inappropriate medicines (PIMs) (Urfer, Elzi, Dell-Kuster, \& Bassetti, 2016). To identify the use of PIMs, extrinsic criteria, such as Start/Stop (Screening Tool to Alert doctors to the Right Treatment/Screening Tool of Older Persons' Prescriptions) (O'mahony et al., 2015) and Beers criteria, updated in 2012 (Campanelli, 2012), are used.

\section{2 | BACKGROUND}

The use of medication in OP is a public health problem (Kim, Shin, Kim, \& Park, 2014) because the older people consume approximately one-third of all prescribed drugs (Eiras et al., 2016). The prevalence of polypharmacy varies according to the scope and country of study. In Spain, previous studies have reported that OP generate three

\section{What does this paper contribute to the wider global clinical community?}

- It is the first study with a large sample that analyses the prevalence, associated factors and temporal trends of polypharmacy and self-medication among Spanish older people in the periods 2006-2014.

- Our study shows the associated factors with polypharmacy and self-medication in Spanish older people. In addition, the prevalence of polypharmacy and prevalence of self-medication are increasing in older people from 2006-2014 in Spain.

- In spite of there are no consensus in the use of medicaments to treat cholesterol, there were an increase in their consumption by Spanish older people.

times as much healthcare demand as the average population and generate $75 \%$ of pharmaceutical expenditures (Núñez et al., 2014). However, the studies conducted in Spain on polypharmacy are scarce, and the prevalence of OP with polypharmacy in the community ranges from 20.6\% -45\% (Blanco-Reina, Ariza-Zafra, Ocaña-Riola, León-Ortíz, \& Bellido-Estévez, 2015; Frutos, Martín, \& Galindo, 2011; Garrido-Garrido et al., 2011; Martin-Pérez et al., 2017), being higher in the hospital setting (92.4\%) according to Agustí, Formiga, and San-José (2017). In addition, most of the existing studies do not include nationally representative samples, and none of them provide updated data for the past 5 years.

On the other hand, referring to Spain, community nurses are the health professionals that have most direct contact with OP (DiosGuerra, Carmona-Torres, Ruíz-Gándara, Muñoz-Alonso, \& RodríguezBorrego, 2015) and who have an important task in the area of educational health. Community nurses must help OP to deal with medications, for preventing the negative consequences of self-medication and polypharmacy (Dios-Guerra \& Pérula de Torres, 2012).

Therefore, the objective of this study was to analyse the prevalence, associated factors and evolution over time of polypharmacy and self-medication in OP from 2006-2014 in Spain.

\section{3 | METHODS}

\subsection{Design and study population}

This was a cross-sectional descriptive study. The sources of information were the National Health Survey in Spain (NHSS) 2006 (Ministerio de Sanidad Servicios Sociales e Igualdad 2006) and 
2011/2012 (Ministerio de Sanidad Servicios Sociales e Igualdad 2013) and the European Health Survey in Spain (EHSS) 2009 (Ministerio de Sanidad Servicios Sociales e Igualdad 2010) and 2014 (Ministerio de Sanidad Servicios Sociales e Igualdad 2015), performed by the National Institute of Statistic (NIS) and the Ministry of Health, Social Services and Equality (MHSSE). These surveys are conducted in noninstitutionalised individuals through personalised interviews. They use a three-stage sampling design with stratification in the first stage: the first-stage units are the census tracts, the second-stage units are the family dwellings, and the third-stage units are the surveyable people present in the home. The firststage units are grouped into strata according to the size of the municipality to which the sections belong. Each participant is assigned a weighting coefficient to ensure the representativeness of the sample. Microdata are available and anonymous; therefore, no special permits were required for their use. The study population was restricted to people aged $\geq 65$ years, living in Spain. The total number of records used was 26,277 : 7,835 in 2006; 6,026 in 2009; 5,896 in 2011/2012; and 6,520 in 2014

\section{2 | Variables}

The variables included in each registry were age (this variable was categorised in groups of age), sex, nationality, domestic partnership, marital status, level of education, perceived contributory pension, bedridden during the last 2 weeks, body mass index (BMI), social class, consumption of medications in the last 2 weeks prescribed by a physician, consumption of medications in the last 2 weeks not prescribed by a physician and medications consumed (for cold/flu/ throat/bronchi, pain, fever, vitamins and minerals, laxatives, antibiotics, tranquillisers/relaxants/sleeping pills, allergy, diarrhoea, rheumatism, heart, blood pressure, stomach and/or digestive disorders, antidepressants/stimulants, cholesterol, diabetes, thyroid, homoeopathic, naturopathic and other medications).

Social class was established according to the categories proposed by the Spanish Society of Epidemiology (Domingo-Salvany et al., 2013).

The polypharmacy variable was calculated from an identical question in all questionnaires: "I will now read you a list of medication types, please tell me which one or which of them have you consumed in the last two weeks, and which ones were prescribed by a physician?" based on groups of medications used to treat diseases/ symptoms, including colds/flu/throat/bronchi, pain, fever, laxatives and antibiotics. Participants were classified as polypharmacy (yes/no) if they answered yes to five or more questions about the consumption of different medication groups in the last 2 weeks. Although there is no consensus yet on the number of medication that must be consumed to be considered polypharmacy, this figure (five medications) has been used in recent studies conducted in different countries (Eiras et al., 2016; Gnjidic et al., 2012; Lopes et al., 2016; Urfer et al., 2016).

The self-medication variable was calculated based on whether the respondent had answered yes to the question "During the last two weeks, have you taken any medications, including herbal medicines or vitamins that were not prescribed by a physician?"

\section{3 | Process}

The research team contacted NIS to determine access to microdata. The different microdata files (Ministerio de Sanidad Servicios Sociales e Igualdad 2006, 2010, 2013, 2015) were downloaded, and a single database was created. To make a comparison of the data in each of the years of the survey, they were recorded according to the established methodology, expressed in the section variables. Finally, we performed a statistical analysis and an interannual comparison.

\section{4 | Statistical analysis}

A descriptive analysis was performed by calculating counts ( $n$ ) and proportions (\%) for qualitative variables and by calculating means and standard deviations (SD) for quantitative variables. A comparison of categorical variables was performed using chi-square tests for contingency tables. In addition, a logistic regression was performed to identify the variables associated with polypharmacy and self-medication. Odds ratios (OR) were calculated with their respective $95 \%$ confidence intervals $(95 \% \mathrm{Cl})$.

All hypothesis comparisons were bilateral, and in all statistical tests, "significant" values were those whose confidence levels were $95 \%(p<.05)$. The statistical analysis was performed with IBM SPSS Statistics version 22 (IBM Corp, Armonk, NY, USA), licensed to the University of Castilla La Mancha.

\section{\begin{tabular}{l|l}
4 & RESULTS
\end{tabular}}

The total sample was 26,277 records of OP, including $62 \%$ women and $38 \%$ men, with a mean age of 75.59 years $(S D \pm 7.19)$. A total of $98 \%$ of the OP were of Spanish nationality, and $48.4 \%$ lived with partners. The most frequent sociodemographic characteristics of the OP were that they were married (49.2\%), had primary or secondary school education (44.6\%), had a contributory pension (95.1\%), had not been bedridden during the last 2 weeks, belonged to social class $\mathrm{V}(26.5 \%)$ and were overweight (38.6\%). Table 1 shows the sociodemographic characteristics of the participants according to the year of the interview.

The mean medication consumption in participants was 2.96 $(S D \pm 2.11)$ (Figure 1). Polypharmacy ( $\geq 5$ medications consumed in the last 2 weeks) was present in $21.9 \%$ of the participants, with an average consumption of 6.11 ( $S D \pm 1.36$ ). Hyperpolypharmacy or excessive polypharmacy $(\geq 10$ medications consumed in the last 2 weeks) was present in $0.6 \%$ of participants. The medications most consumed in the sample were medications for blood pressure (51.6\%), pain (42.8\%) and cholesterol (28.2\%); tranquillisers, relaxants and sleeping pills (24.4\%); and medications for stomach and/or 
TABLE 1 Sociodemographic characteristics of Spanish people over 65 years $(N=26,277)(2006-2014)$

\begin{tabular}{|c|c|c|c|c|}
\hline $\begin{array}{l}\text { Characteristics } \\
n(\%)\end{array}$ & $\begin{array}{l}2006 \\
n=7,835 \text { (\%) }\end{array}$ & $\begin{array}{l}2009 \\
n=6,026(\%)\end{array}$ & $\begin{array}{l}2011 / 2012 \\
n=5,896 \text { (\%) }\end{array}$ & $\begin{array}{l}2014 \\
n=6,520(\%)\end{array}$ \\
\hline \multicolumn{5}{|l|}{ Sex } \\
\hline Male & $2,813(35.9)$ & $2,330(38.7)$ & $2,223(37.7)$ & $2,624(40.2)$ \\
\hline Female & $5,022(64.1)$ & $3,696(61.3)$ & $3,673(62.3)$ & 3,896 (59.8) \\
\hline \multicolumn{5}{|l|}{ Age group (years) } \\
\hline $65-74$ & $3,931(50.2)$ & $2,849(47.3)$ & $2,731(46.3)$ & $3,125(47.9)$ \\
\hline $75-84$ & $3,157(40.3)$ & $2,426(40.3)$ & $2,350(39.9)$ & $2,423(37.2)$ \\
\hline$\geq 85$ & $747(9.5)$ & $751(2.5)$ & 815 (13.8) & $972(14.9)$ \\
\hline \multicolumn{5}{|l|}{ Domestic partnership } \\
\hline Yes & Not registered & $2,925(48.5)$ & Not registered & $3,145(48.3)$ \\
\hline No & & $3,098(51.4)$ & & $3,365(51.6)$ \\
\hline \multicolumn{5}{|l|}{ Marital status } \\
\hline Single & Not registered & $536(8.9)$ & 489 (8.3) & $554(8.5)$ \\
\hline Married & & $2,926(48.6)$ & $2,912(49.4)$ & $3,234(49.6)$ \\
\hline Widowed & & $2,396(39.8)$ & $2,310(39.2)$ & $2,502(38.4)$ \\
\hline Separated & & $84(1.4)$ & $84(1.4)$ & 105 (1.6) \\
\hline Divorced & & 79 (1.3) & $96(1.6)$ & 119 (1.8) \\
\hline \multicolumn{5}{|l|}{ Nationality } \\
\hline Spanish & Not registered & $5,943(98.6)$ & $5,827(98.8)$ & 6,442 (98.8) \\
\hline Foreigner & & $83(1.4)$ & $69(1.2)$ & $78(1.2)$ \\
\hline \multicolumn{5}{|l|}{ Level of education } \\
\hline Without studies & Not registered & $2,805(46.6)$ & Not registered & $2,230(34.2)$ \\
\hline Primary & & $2,376(39.5)$ & & $3,209(49.2)$ \\
\hline Secondary or PT & & $478(7.9)$ & & $564(8.7)$ \\
\hline University & & $355(5.9)$ & & $517(7.9)$ \\
\hline \multicolumn{5}{|l|}{ Bedridden } \\
\hline Yes & Not registered & Not registered & $418(7.1)$ & $531(8.2)$ \\
\hline No & & & $5,478(92.9)$ & $5,987(91.8)$ \\
\hline \multicolumn{5}{|l|}{ Social class } \\
\hline Class I & $313(4)$ & Not registered & $417(7.1)$ & $482(7.4)$ \\
\hline Class II & $416(5.3)$ & & $309(5.2)$ & $416(6.4)$ \\
\hline Class III & $1,899(24.2)$ & & 869 (14.7) & $1,030(15.8)$ \\
\hline Class IV & $1,644(21)$ & & 821 (13.9) & $1,053(16.2)$ \\
\hline Class V & $943(12)$ & & $2,106(35.7)$ & $2,312(35.5)$ \\
\hline Class VI & $1,468(18.7)$ & & 991 (16.8) & $976(15)$ \\
\hline No answer & 1,152 (14.7) & & $383(6.5)$ & 251 (3.8) \\
\hline \multicolumn{5}{|l|}{$\mathrm{BMl}^{\mathrm{a}}$} \\
\hline Insufficient & Not registered & $56(0.9)$ & $47(0.8)$ & $69(1.1)$ \\
\hline Normal weight & & $1,490(24.7)$ & $1,370(23.2)$ & $1,829(28.1)$ \\
\hline Overweight & & $2,361(39.2)$ & $2,116(35.9)$ & $2,644(40.6)$ \\
\hline Obesity & & $1,210(20.1)$ & 1,158 (19.6) & $1,369(21)$ \\
\hline No answer & & 909 (15.1) & 1,205 (20.4) & 609 (9.3) \\
\hline
\end{tabular}

BMI, body mass index; PT, professional training.

${ }^{\mathrm{a}}$ The valour considered for calculating BMI were insufficient $<18.5$; normal weight $18.5-25$; overweight 25-30; and obesity $>30$. digestive disorders (24.2\%) and for the heart (20.3\%). Polypharmacy increased in prevalence according to the years of study $(p<.001)$, showing a higher prevalence in 2014 , as did self-medication $(p<.001)$. The prevalence rates of the different groups of medications consumed and their evolution over time are shown in Figures 2 and 3 . 
Regarding self-medication (Figure 2), only $7.79 \%$ of the OP in 2009 were self-medicated, a proportion that increased to $13.3 \%$ in $2014(p<.001)$. This variable was not included in the NHSS 2006 and $2011 / 2012$.

Table 2 shows the sociodemographic characteristics of the participants by polypharmacy groups and self-medication groups.

In the logistic regression analysis (Table 3), we observed that polypharmacy was associated with sex, women have 1.82 times more likely to have polypharmacy than men $(95 \% \mathrm{Cl}, 1.56-2.12)$ $(p<.001)$; age: people aged $75-84$ years have 1.44 times more likely to have polypharmacy than those aged $65-74$ years $(95 \% \mathrm{Cl}$, 1.24-1.67) $(p<.001)$; marital status: separated/divorced/widowed people have 1.38 times more likely to have polypharmacy than single people (95\% Cl, 1.06-1.79) ( $p=.015$ ); level of education: OP without studies have 2.12 times more likely to have polypharmacy than OP with university education $(95 \% \mathrm{Cl}, 1.59-2.81)(p<.001)$; BMl: overweight or obese people have 1.65 times more likely to have polypharmacy than those with normal weight $(95 \% \mathrm{Cl}, 1.41-1.92)$ $(p<.001)$; bed rest: people who had been bedridden during the last week have 3.75 times more likely to have polypharmacy than those not bedridden (95\% Cl, 3.01-4.68) ( $p<.001)$; and self-medication: self-medicated OP have 1.45 times more likely to have polypharmacy than non-self-medicated OP $(95 \% \mathrm{Cl}, 1.2-1.75)(p<.001)$.

The logistic regression analysis (Table 4) shows that self-medication is associated with female sex (OR, 1.49; 95\% Cl, 1.25-1.77) $(p<.001)$; education level: OP with university education have 1.92 times more likely to self-medicate than those without studies $(95 \%$ $\mathrm{Cl}, 1.43-2.58)(p<.001)$; and BMI: obese or overweight OP have 1.27 times more likely to self-medicate than those of normal weight (95\% Cl, 1.05-1.54) ( $p=.013)$.

\section{5 | DISCUSSION}

Polypharmacy is a public health problem that is increasing with the passage of time due to the increase in life expectancy and the characteristics derived from ageing. Our data broaden the information of previous studies conducted in Spain (Blanco-Reina et al., 2015; Frutos et al., 2011; Garrido-Garrido et al., 2011; Martin-Pérez et al., 2017). Like the previous literature (Charlesworth, Smit, Lee, Alramadhan, \& Odden, 2015; Martin-Pérez et al., 2017; Nishtala \& Salahudeen, 2015), our data show that there has been an increase in the number of medications consumed by the older population in recent years. This increase in medication use is possibly the result of a combination of factors, such as increased chronicity and morbidity, irrational drug use and increased availability of drugs (Blanco-Reina et al., 2015; Fried et al., 2014; Lopes et al., 2016; Wang et al., 2015). Although increasing medication use may mean greater access to treatments and better approaches to disease, polypharmacy is becoming a critical problem, as it causes a multitude of problems for the older person (even if prescribed), such as increased adverse drug reactions, side effects, hospitalisations, falls and use of PIMs (Charlesworth et al., 2015; Lutz et al., 2017; Maher et al., 2014), which are associated with an increased risk of mortality (Gómez et al., 2015).

In our study, the most commonly used medication was for blood pressure, as was seen in another study in China (Wang et al., 2015). This observation may be due to the fact that hypertension is one of the most common pathologies in Spain, with a prevalence of $90 \%$ in those older than 75 years (Menéndez et al., 2016). The second most commonly used medication was analgesics, which coincides with another study in Ethiopia, where pain medications were the most consumed (Eticha \& Mesfin, 2014). This data may be due to the increase in chronic pain with age and because many of these drugs can be bought without prescription (Baldoni et al., 2014; Eticha \& Mesfin, 2014). It is surprising that the consumption of cholesterol medications increased from 2006-2014, as recent studies have reported that there is a lack of evidence for the use of drugs to reduce cholesterol levels because, despite the increase in consumption, there has not been a significant decrease in cholesterol levels. Therefore, medical and scientific associations do not recommend the routine prescription of cholesterol-lowering medication in adults over

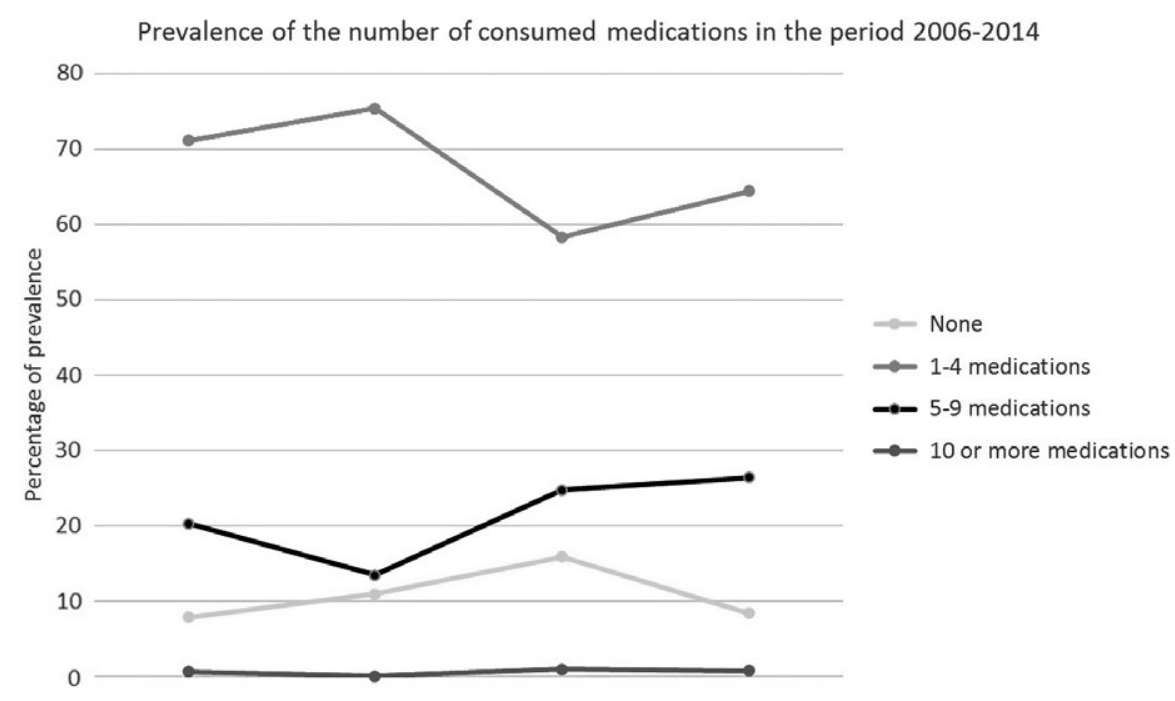

FIGURE 1 Prevalence of the number of consumed medications by Spanish people over 65 years in the period 2006-2014 
Prevalence by type of consumed medications in the period 2006-2014

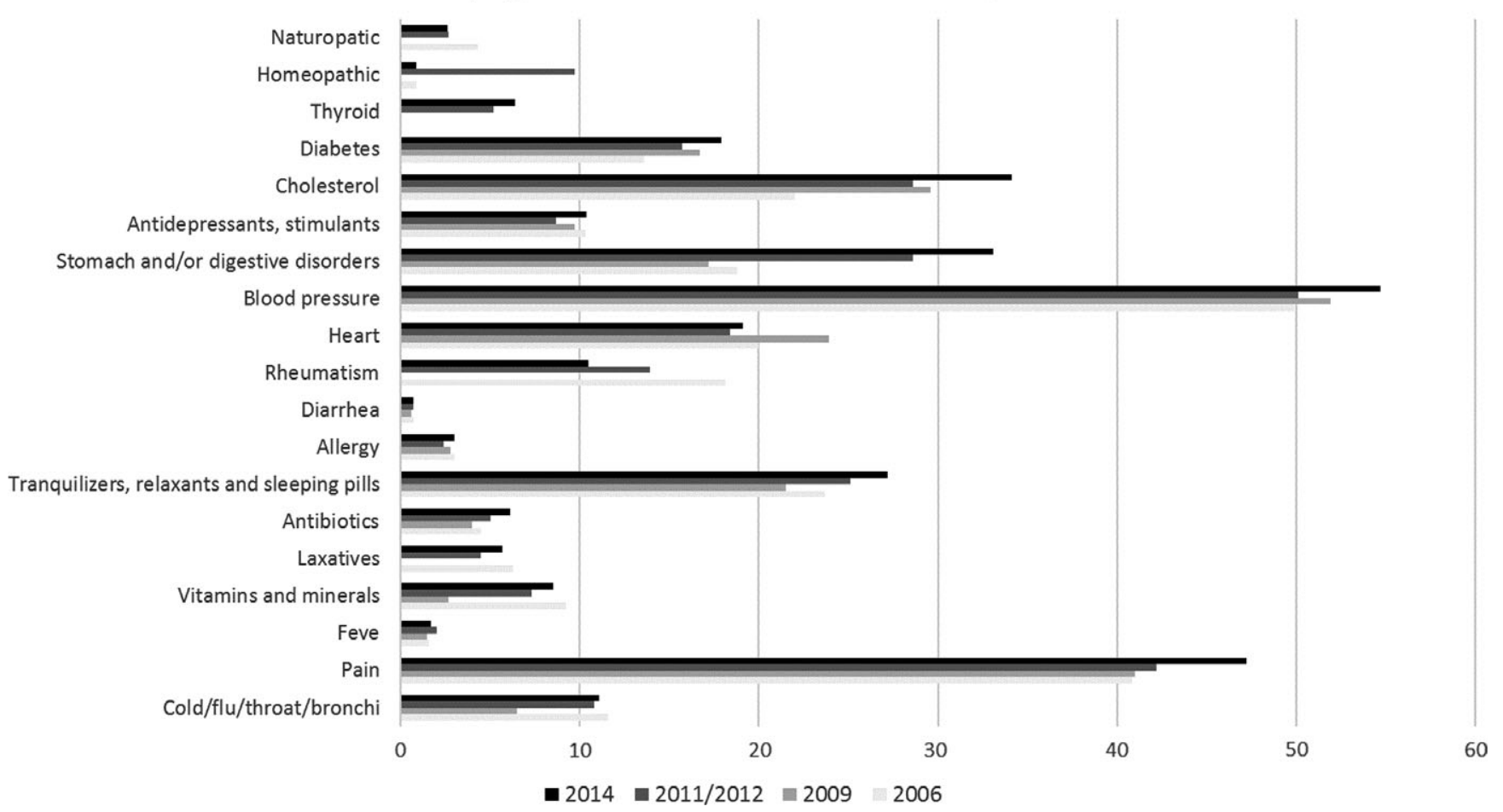

FIGURE 2 Prevalence of the different groups of consumed medications by Spanish people over 65 years in the period $2006-2014$

FIGURE 3 Prevalence of polypharmacy and self-medication in Spanish people over 65 years in the period 2006-2014
Prevalence of Polypharmacy and Self-medication in the period 2006-2014

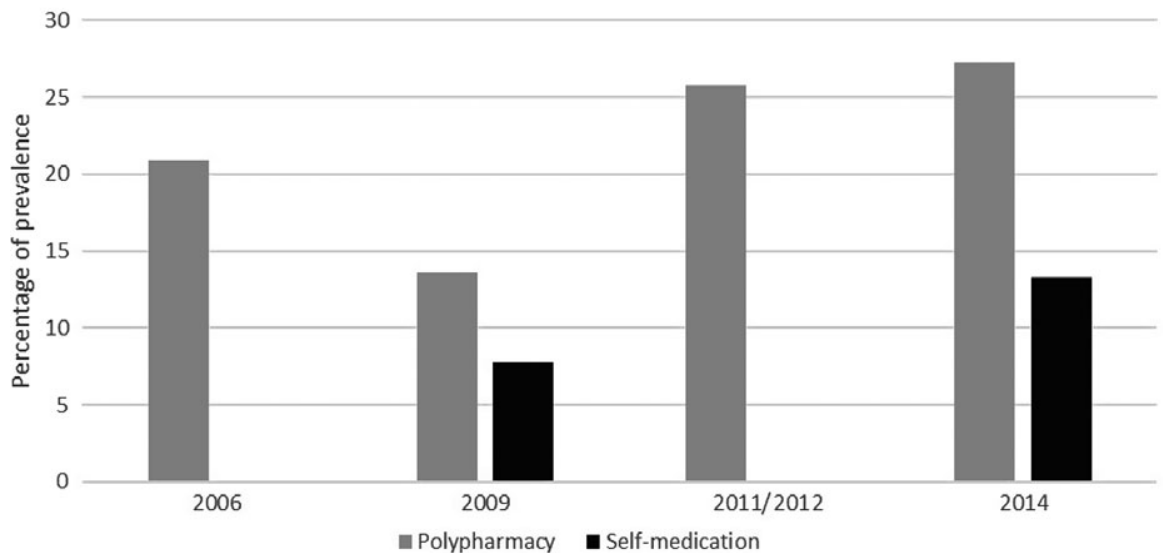

70 years old (Charlesworth et al., 2015). Also surprising is the increased consumption of tranquillisers, relaxants and sleeping pills from 2006-2014, although studies have shown that most benzodiazepines are PIMs and are not recommended as first-line drugs to treat insomnia due to the negative effects they cause, such as cognitive impairment or falls (Pek et al., 2017).

In Spain, the incidence rates of polypharmacy ( $\geq 5$ medications) and hyperpolypharmacy (or excessive polypharmacy, $\geq 10$ medications) in OP living at home (not in a hospital setting) are lower than in other countries using nationally representative samples, such as the United States (Charlesworth et al., 2015) or New Zealand (Nishtala \& Salahudeen, 2015). The existence of studies that consider polypharmacy to be the consumption of $\geq 4$ medications and the lack of consensus on the definition of polypharmacy limit the comparison of our results with other studies. Likewise, data on self-medication are also inferior to other studies conducted in other countries, such as Portugal (Baldoni et al., 2014) or Colombia (Machado-Alba et al., 2014), because in Spain, there is less dispensation of medications without prescription compared with other countries.

Among the risk factors associated with polypharmacy in our study, it is observed, as in other studies, that it is associated with being a woman (Martin-Pérez et al., 2017; Nishtala \& Salahudeen, 2015; Santos et al., 2013), being older (Charlesworth et al., 2015; Kim et al., 2014), being separated/divorced/widowed (Santos et al., 2013), having a lower education level (Martínez-Arroyo, Gomez-Garcia, \& Sauceda-Martínez, 2014) and self-medicating (Eticha \& Mesfin, 2014; Lutz et al., 2017; Mortazavi et al., 2016). However, there are 
TABLE 2 Sociodemographic characteristics of Spanish people over 65 years $(N=26,277)(2006-2014)$

\begin{tabular}{|c|c|c|c|c|c|c|}
\hline \multirow[b]{2}{*}{$\begin{array}{l}\text { Characteristics } \\
n(\%)\end{array}$} & \multicolumn{2}{|l|}{ Polypharmacy } & \multirow[b]{2}{*}{$p$-Value } & \multicolumn{2}{|c|}{ Self-medication } & \multirow[b]{2}{*}{$p$-Value } \\
\hline & $\begin{array}{l}\text { Yes } \\
n=5,753(\%)\end{array}$ & $\begin{array}{l}\text { No } \\
n=20,524 \text { (\%) }\end{array}$ & & $\begin{array}{l}\text { Yes } \\
n=7,399(\%)\end{array}$ & $\begin{array}{l}\text { No } \\
n=18,878(\%)\end{array}$ & \\
\hline Male & $1,520(26.4)$ & $8,470(41.3)$ & \multirow[t]{2}{*}{$<.001$} & $2,566(34.7)$ & $7,424(39.3)$ & \multirow[t]{2}{*}{$<.001$} \\
\hline Female & $4,233(73.6)$ & $12,054(58.7)$ & & $4,833(65.3)$ & $11,454(60.7)$ & \\
\hline $75-84$ & $2,591(45)$ & 7,765 (37.8) & \multirow{2}{*}{$<.001$} & $2,992(40.4)$ & $7,364(39)$ & \multirow{2}{*}{.093} \\
\hline$\geq 85$ & $860(15)$ & $2,425(11.8)$ & & 899 (12.2) & $2,386(12.6)$ & \\
\hline \multicolumn{7}{|c|}{ Domestic partnership } \\
\hline Yes & $1,087(41.9)$ & $4,983(50.1)$ & $<.001$ & $2,920(48.4)$ & $3,150(48.5)$ & .061 \\
\hline Married & $1,756(42.7)$ & $7,316(51.1)$ & \multirow{4}{*}{$<.001$} & $3,159(48.3)$ & $5,913(49.7)$ & \multirow{4}{*}{.107} \\
\hline Widowed & $1,987(48.3)$ & $5,221(36.4)$ & & $2,651(40.5)$ & $4,557(38.3)$ & \\
\hline Separated & $57(1.4)$ & $216(1.5)$ & & $93(1.4)$ & $180(1.6)$ & \\
\hline Divorced & $61(1.5)$ & $233(1.6)$ & & $102(1.6)$ & $192(1.6)$ & \\
\hline \multicolumn{7}{|l|}{ Nationality } \\
\hline Spanish & 4,088 (99.4) & 14,124 (98.6) & \multirow[t]{2}{*}{$<.001$} & 6,450 (98.6) & 11,762 (98.8) & \multirow[t]{2}{*}{.085} \\
\hline Foreigner & $26(0.6)$ & 204 (1.4) & & $92(1.4)$ & $138(1.2)$ & \\
\hline \multicolumn{7}{|l|}{ Level of education } \\
\hline Without studies & $1,280(49.4)$ & 3,755 (37.8) & $<.001$ & $2,727(45.2)$ & $2,308(35.5)$ & $<.001$ \\
\hline Social class & & & & & & \\
\hline Class I & $218(4.5)$ & $994(6.5)$ & $<.001$ & $143(7.5)$ & $1,059(5.8)$ & $<.001$ \\
\hline Class II & $224(4.5)$ & $917(6)$ & & $140(6.9)$ & $1,001(5.5)$ & \\
\hline Class III & $834(16.9)$ & $2,964(19.3)$ & & $414(20.4)$ & $3,384(18.6)$ & \\
\hline Class IV & $829(16.8)$ & $2,689(17.6)$ & & 387 (19.1) & 3,131 (17.2) & \\
\hline Class V & $1,406(28.5)$ & $3,955(25.8)$ & & 435 (21.4) & $4,926(27)$ & \\
\hline Class VI & $988(20)$ & 2,447 (16) & & 319 (15.7) & $3,116(17.1)$ & \\
\hline No answer & $434(8.8)$ & 1,352 (8.8) & & $180(8.9)$ & $1,606(8.8)$ & \\
\hline $\mathrm{BMl}^{\mathrm{a}}$ & & & & & & \\
\hline Insufficient & $44(1.1)$ & $128(0.8)$ & $<.001$ & $66(1)$ & $106(0.9)$ & .332 \\
\hline Normal weight & 782 (19) & 3,907 (27.3) & & $1,611(24.6)$ & $3,078(25.9)$ & \\
\hline Overweight & $1,493(36.3)$ & $5,628(39.3)$ & & $2,563(39.2)$ & $4,558(38.3)$ & \\
\hline Obesity & $1,132(27.5)$ & $2,605(18.2)$ & & $1,345(20.6)$ & 2,392 (20.1) & \\
\hline No answer & $663(16.1)$ & $2,060(14.4)$ & & 957 (14.6) & $1,766(14.8)$ & \\
\hline
\end{tabular}

BMI, body mass index; PT, professional training.

${ }^{a}$ The valour considered for calculating BMI were insufficient $<18.5$; normal weight 18.5-25; overweight 25-30; and obesity $>30$. 
TABLE 3 Logistic regression model for the association between sociodemographic characteristics and polypharmacy in Spanish people over 65 years (2006-2014)

\begin{tabular}{|c|c|c|}
\hline & OR (95\% Cl) & $p$-Value \\
\hline \multicolumn{3}{|l|}{ Sex } \\
\hline Male & Reference & \\
\hline Female & $1.82(1.56-2.12)$ & $<.001$ \\
\hline \multicolumn{3}{|l|}{ Age group (years) } \\
\hline $65-74$ & Reference & \\
\hline $75-84$ & $1.44(1.24-1.67)$ & $<.001$ \\
\hline$\geq 85$ & $1.4(1.14-1.71)$ & .001 \\
\hline \multicolumn{3}{|l|}{ Marital status } \\
\hline Single & Reference & \\
\hline Married & $1.3(1-1.69)$ & .05 \\
\hline Separated/divorced/widowed & $1.38(1.06-1.79)$ & .015 \\
\hline \multicolumn{3}{|l|}{ Level of education } \\
\hline Without studies & $2.12(1.59-2.81)$ & $<.001$ \\
\hline Primary & $1.32(1-1.74)$ & .048 \\
\hline Secondary or PT & $1.06(0.75-1.52)$ & .731 \\
\hline University & Reference & \\
\hline \multicolumn{3}{|l|}{ BMI } \\
\hline Normal weight (18.5-25) & Reference & \\
\hline Insufficient (<18.5) & $1.7(0.9-3.2)$ & .103 \\
\hline Overweight or Obesity $(\geq 25)$ & $1.65(1.41-1.92)$ & $<.001$ \\
\hline \multicolumn{3}{|l|}{ Bedridden } \\
\hline No & Reference & \\
\hline Yes & $3.75(3.01-4.68)$ & $<.001$ \\
\hline \multicolumn{3}{|l|}{ Self-medication } \\
\hline No & Reference & \\
\hline Yes & $1.45(1.2-1.75)$ & $<.001$ \\
\hline
\end{tabular}

$\mathrm{BMI}$, body mass index; $\mathrm{Cl}$, confidence interval; OR, odds ratio; $\mathrm{PT}$, professional training.

no known previous studies that have linked polypharmacy with higher BMI and bed rest. This may be because overweight/obesity is a risk factor for many diseases and therefore requires a greater number of drugs for treatment. Being bedridden during the last 2 weeks may suggest that the person has been ill and thus the reason for self-medication.

Among the factors associated with self-medication are female sex and higher education level, as in previous studies (Baldoni et al., 2014; Machado-Alba et al., 2014). In addition, in our study, selfmedication was associated with a higher BMI, that it would be possible due to the association between obesity and other diseases, which require more medications.

\section{1 | Limitations}

Among the limitations of our study, whose sources have been the records of the NHSS and EHSS, which are cross-sectional studies,
TAB LE 4 Logistic regression model for the association between Sociodemographic Characteristics with self-medication in Spanish people over 65 years (2006-2014)

\begin{tabular}{|lcc|}
\hline \multicolumn{1}{l}{ OR $(95 \% \mathrm{Cl})$} & $p$-Value \\
\hline Sex & & \\
\hline Male & Reference & \\
\hline Female & $1.49(1.25-1.77)$ & $<.001$ \\
\hline Level of education & & \\
\hline Without studies & Reference & .052 \\
\hline Primary & $1.22(1-1.48)$ & .026 \\
\hline Secondary or PT & $1.42(1.04-1.93)$ & \\
\hline University & $1.92(1.43-2.58)$ & $<.001$ \\
\hline BMI & & \\
\hline Normal weight (18.5-25) & Reference & .84 \\
\hline Insufficient $(<18.5)$ & $1.09(0.48-2.46)$ & .013 \\
\hline Overweight or Obesity $(\geq 25)$ & $1.27(1.05-1.54)$ & .013 \\
\hline
\end{tabular}

$\mathrm{BMI}$, body mass index; $\mathrm{Cl}$, confidence interval; $\mathrm{OR}$, odds ratio; $\mathrm{PT}$, professional training.

we were not able to determine the causal direction between polypharmacy and the related variables. In addition, NHSS and EHSS did not collect variables that may influence polypharmacy, such as type of self-administered medication, previous hospital admissions, PIMs, previous chronic diseases and health status. It is advisable to include these variables in future studies. However, the current study has great strength because the data were obtained from national representative surveys with a large number of participants and represent a step towards gaining knowledge of this problem in today's society.

\section{6 | CONCLUSION}

In conclusion, the prevalence of polypharmacy is considerable and increased significantly from 2006-2014. Polypharmacy is associated with sex (female), being older, being separated/divorced/widowed, being without studies, having a higher BMI, being bedridden during the last 2 weeks and self-medicating. In addition, there were increases in the consumption of medicaments to treat cholesterol and tranquillisers/relaxants/sleeping pills, when there is no consensus in their use because there is evidence that they do not have sufficient therapeutic efficacy, in the case of statins, and that they cannot overcome the side effects of the therapeutic effect, in the case of the benzodiazepines, which is why medical and scientific associations have recommended not to use them. However, selfmedication in Spain has a lower prevalence than in other countries, although the gradual increase in time is cause for concern, and it is associated with the female sex, lack of university education and higher BMI. Therefore, it is considered necessary to raise awareness among health professionals, specially nurses, and to implement programmes to mitigate the problem. 


\section{7 | RELEVANCE TO CLINICAL PRACTICE}

Health professionals, in particular nursing, should be aware of this global public health problem and should develop strategies to prevent it. It can be possible to prevent the fatal consequences of polypharmacy such as event adverse, falls or hospital admissions, through the knowledge of the risk factors for polypharmacy, especially in noninstitutionalised OP. In Spain, community nurses perform the highest number of home visits (Dios-Guerra et al., 2015), so they have an important role for preventing polypharmacy and self-medication, because they provide support with the use of medications (Westerbotn, Fahlström, Fastbom, Agüero-Torres, \& Hillerås, 2008). The nurses have the opportunity to assist in minimising the use of medications and selfmedications and have also the opportunity to lead initiatives aiming to educate interdisciplinary team members and patients on improved medication management practices (Kim \& Parish, 2017).

It will be necessary to develop protocols to be implemented in primary care physician's offices to reduce this problem, which can have fatal consequences for the older person (Lutz et al., 2017). Although Spain has established the improvement of care for patients with polypharmacy as one of the priorities of health services and has initiated specific programmes such as that performed in the region of Galicia (Reboredo-García, Mateo, \& Casal-Llorente, 2014), the results show that the number of people with polypharmacy continues to grow. For this reason, it is considered necessary to establish innovative clinical strategies in which the nurse, the physician and the patient are involved to combat polypharmacy to reduce the risks and costs of medicines and to develop protocols for action (Charlesworth et al., 2015). In addition, it appears necessary to include specific programmes on this problem in the university studies of health professions as nursing degree to raise the awareness of future professionals and help to reduce the problem. Increased consumption rates of cholesterol medications and tranquillisers/relaxants/sleeping pills justify further studies exploring the causes and consequences of this usage, especially when the literature does not recommend the use of statins and benzodiazepines due to lack of scientific evidence of their efficacy. Continuous reassessments of the medication regime and current clinical status of OP by physicians and nurses are required to avoid polypharmacy.

\section{CONFLICT OF INTERESTS}

The authors declare that there are no conflict of interests.

\section{CONTRIBUTIONS}

Study design: JMC-T, AIC-C, BR-A, MAR-B; data collection and analysis: JMC-T, AIC-C and manuscript preparation: JMC-T, AIC-C, BRA, JAL-A, MMM, MAR-B.

\section{ORCID}

Juan Manuel Carmona-Torres (iD http://orcid.org/0000-0002-7781$872 X$
Ana Isabel Cobo-Cuenca (iD http://orcid.org/0000-0001-7873-3835 José Alberto Laredo-Aguilera iD http://orcid.org/0000-0002-36613584

\section{REFERENCES}

Aguirre, N. G., Martínez, A. C., Muñoz, L. B., Avellana, M. C., Marco, J. V., \& Díez-Manglano, J. (2017). Polypathology, polypharmacy, medication regimen complexity and drug therapy appropriateness. Revista Clínica Española, 217(5), 289-295. https://doi.org/10.1016/j.rce. 2016.12.013

Agustí, A., Formiga, F., \& San-José, A. (2017). Polypharmacy and inappropriate prescription of medicines in the elderly. Revista espanola de geriatria y gerontologia, 52(4), 233-234. https://doi.org/10.1016/j.re gg.2016.11.005

Arrais, P. S. D., Fernandes, M. E. P., Pizzol, T. D. S. D., Ramos, L. R., Mengue, S. S., Luiza, V. L., .. Bertoldi, A. D. (2016). Prevalence of self-medication in Brazil and associated factors. Revista de saude publica, $\quad 50, \quad 13 \mathrm{~s} . \quad$ https://doi.org/10.1590/s1518-8787. 2016050006117

Baldoni, A. O., Ayres, L. R., Martinez, E. Z., Dewulf, N. D. L. S., dos Santos, V., \& Pereira, L. R. L. (2014). Factors associated with potentially inappropriate medications use by the elderly according to Beers criteria 2003 and 2012. International Journal of Clinical Pharmacy, 36(2), 316-324. https://doi.org/10.1007/s11096-013-9880-y

Blanco-Reina, E., Ariza-Zafra, G., Ocaña-Riola, R., León-Ortíz, M., \& Bellido-Estévez, I. (2015). Optimizing elderly pharmacotherapy: polypharmacy vs. undertreatment. Are these two concepts related? European Journal of Clinical Pharmacology, 71(2), 199-207. https://doi.org/10. 1007/s00228-014-1780-0

Cabello, A. J. P., Gavilán, E. D. P., Jiménez, F. J. G., Rodríguez, C. M., Del Castillo, J. D. D. L., \& Cañas, E. P. (2016). Drug-related mortality among inpatients: A retrospective observational study. European Journal of Clinical Pharmacology, 72(6), 731-736. https://doi.org/10.1007/ s00228-016-2026-0

Campanelli, C. M. (2012). American Geriatrics Society updated beers criteria for potentially inappropriate medication use in older adults: The American Geriatrics Society 2012 Beers Criteria Update Expert Panel. Journal of the American Geriatrics Society, 60(4), 616-631. https://doi. org/10.1111/j.1532-5415.2012.03923.x

Charlesworth, C. J., Smit, E., Lee, D. S., Alramadhan, F., \& Odden, M. C. (2015). Polypharmacy among adults aged 65 years and older in the United States: 1988-2010. Journals of Gerontology Series A: Biomedical Sciences and Medical Sciences, 70(8), 989-995. https://doi.org/10. 1093/gerona/glv013

Dios-Guerra, C., Carmona-Torres, J. M., Ruíz-Gándara, Á., Muñoz-Alonso, A., \& Rodríguez-Borrego, M. A. (2015). Programmed home visits by nursing professionals to older adults: Prevention or treatment? Revista latino-americana de enfermagem, 23(3), 535-542. https://doi. org/10.1590/0104-1169.0338.2585

Dios-Guerra, C., \& Pérula de Torres, L. Á. (2012). Factors related to Ineffective Handle of Therapeutic Regimen (IHTR) in chronic patients of nursing consultation. Index de Enfermería, 21(1-2), 14-17. https://doi. org/10.4321/S1132-12962012000100004

Domingo-Salvany, A., Bacigalupe, A., Carrasco, J. M., Espelt, A., Ferrando, J., \& Borrell, C. (2013). Proposals for social class classification based on the Spanish National Classification of Occupations 2011 using neo-Weberian and neo-Marxist approaches. Gaceta Sanitaria, 27(3), 263-272. https://doi.org/10.1016/j.gaceta.2012.12. 009

Eiras, A., Teixeira, M. A., Gonzalez-Montalvo, J. I., Castell, M. V., Queipo, R., \& Otero, A. (2016). Consumption of drugs in over 65 in Porto (Portugal) and risk of potentially inappropriate medication prescribing. 
Atencion primaria, 48(2), 110-120. https://doi.org/10.1016/j.aprim. 2015.03.005

Eticha, T., \& Mesfin, K. (2014). Self-medication practices in Mekelle, Ethiopia. PLoS ONE, 9(5), e97464. https://doi.org/10.1371/journal. pone.0097464

Fried, T. R., O'leary, J., Towle, V., Goldstein, M. K., Trentalange, M., \& Martin, D. K. (2014). Health outcomes associated with polypharmacy in community-dwelling older adults: A systematic review. Journal of the American Geriatrics Society, 62(12), 2261-2272. https://doi.org/ 10.1111/jgs.13153

Frutos, B. E., Martín, C. J., \& Galindo, V. P. (2011). Factors related to polypharmacy in the non-institutionalised elderly. Analysis of the subsample of the National Survey of Health 2006 for the elderly in Castile-Leon. Revista espanola de geriatria y gerontologia, 46(6), 303-306. https://doi.org/10.1016/j.regg.2011.03.002

Garrido-Garrido, E. M., García-Garrido, I., García-López-Durán, J. C., García-Jiménez, F., Ortega-López, I., \& Bueno-Cavanillas, A. (2011). Study of polymedicated patients over 65 years-old in an urban primary care centre. Revista de calidad asistencial, 26(2), 90-96. https://doi.org/10.1016/j.cali.2010.10.002

Gnjidic, D., Hilmer, S. N., Blyth, F. M., Naganathan, V., Waite, L., Seibel, M. J., ... Le Couteur, D. G. (2012). Polypharmacy cutoff and outcomes: Five or more medicines were used to identify communitydwelling older men at risk of different adverse outcomes. Journal of Clinical Epidemiology, 65(9), 989-995. https://doi.org/10.1016/j.jcline pi.2012.02.018

Gómez, C., Vega-Quiroga, S., Bermejo-Pareja, F., Medrano, M. J., Louis, E. D., \& Benito-León, J. (2015). Polypharmacy in the elderly: A marker of increased risk of mortality in a population-based prospective study (NEDICES). Gerontology, 61(4), 301-309. https://doi.org/10.1159/ 000365328

Kim, J., \& Parish, A. L. (2017). Polypharmacy and medication management in older adults. Nursing Clinics, 52(3), 457-468. https://doi.org/10. 1016/j.cnur.2017.04.007

Kim, H. A., Shin, J. Y., Kim, M. H., \& Park, B. J. (2014). Prevalence and predictors of polypharmacy among Korean elderly. PLoS ONE, 9(6), e98043. https://doi.org/10.1371/journal.pone.0098043

Lopes, L. M., Figueiredo, T. P. D., Costa, S. C., \& Reis, A. M. M. (2016). Use of potentially inappropriate medications by the elderly at home. Ciencia \& saude coletiva, 21(11), 3429-3438. https://doi.org/10. 1590/1413-812320152111.14302015

López-Soto, P. J., García-Arcos, A., Fabbian, F., Manfredini, R., \& Rodríguez-Borrego, M. A. (2017). Falls suffered by elderly people from the perspective of health care personnel: A qualitative study. Clinical Nursing Research, https://doi.org/10.1177/ 1054773817705532

Lutz, B. H., Miranda, V. I. A., \& Bertoldi, A. D. (2017). Potentially inappropriate medications among older adults in Pelotas, Southern Brazil. Revista de saude publica, 51, 52. https://doi.org/10.1590/S15188787.2017051006556

Machado-Alba, J. E., Echeverri-Cataño, L. F., Londoño-Builes, M. J., Moreno-Gutiérrez, P. A., Ochoa-Orozco, S. A., \& Ruiz-Villa, J. O. (2014). Social, cultural and economic factors associated with self-medication. Biomédica, 34(4), 580-588. https://doi.org/10.1590/S012041572014000400011

Maher, R. L., Hanlon, J., \& Hajjar, E. R. (2014). Clinical consequences of polypharmacy in elderly. Expert Opinion on Drug Safety, 13(1), 57-65. https://doi.org/10.1517/14740338.2013.827660

Martin, A. B., Hartman, M., Benson, J., Catlin, A., \& National Health Expenditure Accounts Team (2016). National health spending in 2014: Faster growth driven by coverage expansion and prescription drug spending. Health Affairs, 35(1), 150-160. https://doi.org/10. 1377/hlthaff.2015.1194

Martínez-Arroyo, J. L., Gomez-Garcia, A., \& Sauceda-Martínez, D. (2014). Polypharmacy prevalence and potentially inappropriate drug prescription in the elderly hospitalized for cardiovascular disease. Gaceta medica de Mexico, 150(1), 29-38.

Martin-Pérez, M., López, D. A. A., Hernández-Barrera, V., Jiménez-García, R., Jiménez-Trujillo, I., Palacios-Ceña, D., \& Carrasco-Garrido, P. (2017). Prevalence of polypharmacy among the population older than 65 years in Spain: Analysis of the 2006 and 2011/12 National Health Surveys. Revista espanola de geriatria y gerontologia, 52(1), 2-8. https://doi.org/10.1016/j.regg.2016.07.006

Menéndez, E., Delgado, E., Fernández-Vega, F., Prieto, M. A., Bordiú, E., Calle, A., ... Gaztambide, S. (2016). Prevalence, diagnosis, treatment, and control of hypertension in Spain. Results of the Di@ bet. Es study. Revista Española de Cardiología, 69(6), 572-578. https://doi. org/10.1016/j.rec.2015.11.034

Ministerio de Sanidad Servicios Sociales e Igualdad (2006). Encuesta Nacional de Salud ENS 2006. Madrid, Spain: Ministerio de Sanidad y Consumo. Retrieved from http://www.msssi.gob.es

Ministerio de Sanidad Servicios Sociales e Igualdad \& Instituto Nacional de Estadística (2010). Encuesta Europea de Salud en España EESE 2009. Madrid, Spain: Ministerio de Sanidad, Servicios Sociales e Igualdad. Retrieved from www.ine.es

Ministerio de Sanidad Servicios Sociales e Igualdad \& Instituto Nacional de Estadística (2013). Encuesta Nacional de Salud España ENSE 2011/ 12. Madrid, Spain: Ministerio de Sanidad, Servicios Sociales e Igualdad. Retrieved from www.ine.es

Ministerio de Sanidad Servicios Sociales e Igualdad \& Instituto Nacional de Estadística (2015). Encuesta Europea de Salud en España EESE 2014. Madrid, Spain: Ministerio de Sanidad Servicios Sociales e Igualdad. Retrieved from www.ine.es

Mortazavi, S. S., Shati, M., Keshtkar, A., Malakouti, S. K., Bazargan, M., \& Assari, S. (2016). Defining polypharmacy in the elderly: A systematic review protocol. British Medical Journal Open, 6(3), e010989. https://doi.org/10.1136/bmjopen-2015-010989

Nishtala, P. S., \& Salahudeen, M. S. (2015). Temporal trends in polypharmacy and hyperpolypharmacy in older New Zealanders over a 9-year period: 2005-2013. Gerontology, 61(3), 195-202. https://doi.org/10. $1159 / 000368191$

Núñez, M. A., Montiel, L. A., Martín, A. E., Torres, V. B., Lara, M. C., \& González, C. J. (2014). Adherence to treatment, by active ingredient, in patients over 65 years on multiple medication. Atencion primaria, 46(5), 238-245. https://doi.org/10.1016/j.aprim.2013.10. 003

O'mahony, D., O'sullivan, D., Byrne, S., O'connor, M. N., Ryan, C., \& Gallagher, P. (2015). STOPP/START criteria for potentially inappropriate prescribing in older people: Version 2. Age and Ageing, 44(2), 213218. https://doi.org/10.1093/ageing/afu145

Pek, E. A., Remfry, A., Pendrith, C., Fan-Lun, C., Bhatia, R. S., \& Soong, C. (2017). High prevalence of inappropriate benzodiazepine and sedative hypnotic prescriptions among hospitalized older adults. Journal of Hospital Medicine, 12(5), 310-316. https://doi.org/10.12788/jhm. 2739

Reboredo-García, S., Mateo, C. G., \& Casal-Llorente, C. (2014). Implantation of a program for polymedicated patients within the framework of the Galician strategy for integrated chronic care. Atencion primaria, 46(3), 33-40. https://doi.org/10.1016/S0212-6567(14) 70063-0

Santos, T. R. A., Lima, D. M., Nakatani, A. Y. K., Pereira, L. V., Leal, G. S., \& Amaral, R. G. (2013). Medicine use by the elderly in Goiania, Midwestern Brazil. Revista de saude publica, 47(1), 94-103. https://doi. org/10.1590/S0034-89102013000100013

United Nations, Department of Economic and Social Affairs, Population Division (2015). World Population Ageing 2015. Report No.: ST/ESA/ SER.A/3902015. Retrieved from http://www.un.org/en/developme nt/desa/population/publications/pdf/ageing/WPA2015_Report.pdf

Urfer, M., Elzi, L., Dell-Kuster, S., \& Bassetti, S. (2016). Intervention to improve appropriate prescribing and reduce polypharmacy 
in elderly patients admitted to an internal medicine unit. PLoS ONE, 11(11), e0166359. https://doi.org/10.1371/journal.pone. 0166359

Wang, R., Chen, L., Fan, L., Gao, D., Liang, Z., He, J., ... Gao, L. (2015). Incidence and effects of polypharmacy on clinical outcome among patients aged 80+: A five-year follow-up study. PLoS ONE, 10(11), e0142123. https://doi.org/10.1371/journal.pone.0142123

Westerbotn, M., Fahlström, E., Fastbom, J., Agüero-Torres, H., \& Hillerås, P. (2008). How do older people experience their management of medicines? Journal of Clinical Nursing, 17(5a), 106-115. https://doi. org/10.1111/j.1365-2702.2007.02151.x
How to cite this article: Carmona-Torres JM, Cobo-Cuenca Al, Recio-Andrade B, Laredo-Aguilera JA, Martins MM, Rodríguez-Borrego MA. Prevalence and factors associated with polypharmacy in the older people: 2006-2014. J Clin Nurs. 2018;27:2942-2952. https://doi.org/10.1111/ jocn.14371 